\title{
PARENTÉTICOS Y SALTOS REFERENCIALES EN EL DEBATE POLÍTICO. RELACIONES
}

\author{
MARÍA MATILDE CAMACHO ADARVE \\ Grupo ILSE. Universidad de Almería
}

\section{RESUMEN}

Si el presente artículo se inició con el objetivo de observar la naturaleza y funciones de las unidades discursivas parentéticas en el género debate -subgénero político-, una vez observado su funcionamiento, surgió la posibilidad de establecer un criterio más general, e incluso previo, en el que se subsumiera el concepto de "parentético", tan variopinto y lábil. Ese criterio resultó ser el de discontinuidad o irregularidad referencial que, a partir de ahora, llamaremos "salto referencial", o solo "salto". No pretende este ser un trabajo estadístico, basado en amplias muestras ni cotejado científicamente, sino, más bien, una serie de impresiones o especulaciones a propósito de las discontinuidades referenciales, entre las que se hallan los parentéticos, que se pueden advertir en el debate televisado por TVE el pasado 14 de diciembre de 2015, entre los contrincantes políticos de los partidos mayoritariamente votados hasta entonces, Mariano Rajoy -como representante del partido conservador Partido Popular (PP) - y Pedro Sánchez -como representante del partido progresista Partido Socialista Obrero Español (PSOE)-.

PALABRAS ClaVE: debate político, segmentos de comentario, unidades parentéticas, digresiones, saltos referenciales, discontinuidades referenciales, interpolaciones parentéticas.

\section{ABSTRACT}

This paper was at first intended to explore the nature and functioning of parenthetical discoursal units in the political debate genre. However, upon closer inspection of the functioning of these units, it was thought appropriate to pin down a more general criterion under which the concept of "parenthetical" could be subsumed. The notion deemed here appropriate for this purpose is that of discontinuous designation or referential twist, which will be referred to throughout this paper as referential leap or leap for short. The research presented here is not meant to be a statistical study based on large quantities of data and backed up in a scientifically rigorous way. Rather, it sets out to offer some impressionistic insights into referential discontinuities, including parentheticals, as attested in the political discussion broadcast on TVE on December $14^{\text {th }}, 2015$, between the leaders of the up to then two major political parties in Spain, namely, Mariano 
Rajoy, as the representative of the conservative party (PP), and Pedro Sánchez, as the representative of the socialist party (PSOE).

KEYWORDS: political debate, comment clauses, parentheticals units, digressions, referential twists, referential discontinuities, parenthetical interpolations.

\section{INTRODUCCIÓN}

\subsection{El debate político como (sub)género}

Como sabemos, todos los textos son susceptibles de agrupación en géneros ${ }^{1}$, en virtud de una serie de propiedades comunes. Los géneros, dependiendo de la inmediatez y de la tecnología en su emisión, pueden ser directos o retransmitidos -como es el caso que nos ocupa-. Y, como todo en el discurso, cada género tendrá sus respectivas caras textual e interactiva.

De modo muy sucinto, pasaremos a caracterizar el debate político retransmitido por televisión, o indirecto, con arreglo a sus particularidades genéricas. Las propiedades textuales de este género consisten en contener un tema especializado (política), con la posibilidad de incluir muchos subtemas que el moderador va proponiendo y cuya disposición, partiendo de la argumentación que se impone a cualquier otra disposición textual, puede presentar fragmentos descriptivos, expositivos o narrativos. Otra característica de este género es el registro culto o medio-culto que usan los participantes activos en él, si se atiende a la máxima difusión ante el auditorio. Asimismo, su estructura contiene partes -cada uno de los bloques temáticos- y subpartes (ya temáticas, ya estructurales formales); además, como unidad, el debate retransmitido puede estar engarzado en otra unidad mayor (un programa televisivo más amplio); ello, al margen de que, considerado género directo, sin retransmitir, constituya una estructura en sí mismo, con la característica de "no susceptible de engarce".

Por su parte, presenta las siguientes propiedades contextual-interactivas, atendiendo a la función social del género; esto es, a las relaciones entre los hablantes y la finalidad del género, que, en el caso del debate político, es transaccional: persuadir para actuar (mover al voto), ofrecer puntos de vista $u$ opiniones (pertinentes para apoyar a sus respectivos partidos políticos), afianzar lazos sociales (de sensación de pertenencia o simpatía a un partido político), hacer reflexionar (al contrincante político y, por extensión a los telespectadores), demostrar hechos, exponiéndolos y argumentándolos con pretendida objetividad y, en la medida de lo posible, adoctrinar a la audiencia.

\footnotetext{
1 Camacho Adarve (2007).
} 
Es de destacar cómo, al tratarse de un género retrasmitido, los participantes en el acto comunicativo se duplican: el emisor primario es el político que ostente el turno de palabra o bien el moderador, mientras el secundario es la televisión. Esto es aplicable a los receptores, si atendemos a qué político escucha -o moderador-, como receptor primario, o si son los televidentes los considerados receptores del formato televisivo. Hay que tener también en cuenta que, a pesar de existir dos escenarios locales -como son el plató, por una parte y cada lugar en donde esté instalado el televisor, por otra- sí es única la ubicación temporal, al ser retransmitido en tiempo real (es decir, que no tendría como propio el rasgo "diferido" y sí el de inmediatez receptiva). Dicho de otro modo, las coordenadas espaciales son compartidas por la duplicidad de emisores y receptores, mientras las locales, no.

Desde el punto de vista de las relaciones entre el formato genérico y sus usuarios, se aprecia un nivel de formalización alto, debido a los papeles preasignados de los hablantes (moderador y oponentes), con sus tiempos, turnos de palabra y tiempos tasados; por consiguiente, apenas hay margen de libertad ni lugar a la improvisación, a pesar de la continua pugna por acaparar la palabra. Además, el papel discursivo de los hablantes, en el marco "primario", es mixto, ya que se muestra fijo y encorsetado-desde el momento en que cada participante tiene, como hemos señalado, su papel fijo-; esto es así porque los contendientes verbales no pueden dejar de serlo y el moderador no debe extralimitarse en llevar el mando en turnos de habla, temas tratados y regulación en materia de cortesía lingüísticodiscursiva, como tampoco intervenir en las argumentaciones emitidas; sin embargo, sí existe intercambiabilidad de papeles discursivos cuando el emisor se convierte en receptor y viceversa. En el marco secundario (televisión/audiencia), se da una rigidez inalterable: la audiencia es receptora $y$, en este sentido, el debate es un género que, a priori, tiene un destinatario ideal universal, y como receptor, no puede intervenir directamente en el acto comunicativo; la propia televisión se erige en emisor único.

Por último, respecto a las relaciones entre los usuarios del género "debate”, subgénero "político", señalaremos que existe, en el marco primario, un cierto grado de distancia social entre los participantes, debido al referido encorsetamiento formal, acompañado de una notable distancia psicológica, entre ellos, por tratarse de antagonistas y de un moderador impasible que ejerce el poder máximo en el formato y conforma una relación asimétrica entre él y los dos políticos. Sin embargo, sí es preceptiva la simetría entre político y político. Ello no implica un máximo grado de aceptación del político emisor al político receptor, sino mínimo, por tratarse de contendientes. En el marco secundario, la televisión, como emisora, pretende que se dé la mínima distancia social y psicológica entre los 
contenidos que emite y sus receptores, porque persigue la máxima audiencia, al margen de que ostente el máximo poder de manipulación, con las técnicas oportunas, pero esto es materia de otro estudio más profundo.

\subsection{Textualidad e interacción}

Como venimos sosteniendo desde 2001 (Camacho Adarve, especialmente 2001 y 2006), si pretendemos tener una visión lo menos fragmentada posible de la comunicación humana mediante la lengua, resulta útil hacer coincidir sobre la misma realidad -el discurso-, dos perspectivas: la perspectiva textual y la perspectiva interactiva, y -lo más importanteinterrelacionarlas, ya que ambas funcionan simultáneamente en el discurso. Adscritas a la dimensión textual se encuentran las operaciones o procedimientos lógico-lingüísticos que el hablante utiliza en el procesamiento ${ }^{2}$, desde la planificación, pasando por la estructuración interna del discurso hasta la expresión lingüística final. La textualidad relaciona de manera más directa e inmediata al emisor con la lógica del pensamiento en forma lingüística. Por su parte, la faceta interactiva del discurso relaciona a emisor y receptor mediante la emisión lingüística; atiende a las relaciones socio-afectivas que se mallan entre hablantes utilizando el lenguaje como vehículo: subjetividades, actitudes, sentimientos, con la cosmovisión particular y colectiva de los hablantes serán las variables que habrá que considerar en esta segunda perspectiva. Sin embargo, hay que admitir que, al margen de la exposición didáctica, no existe una delimitación neta como la que hemos señalado, ya que, repetimos, textualidad e interacción actúan a la vez en el discurso ${ }^{3}$. Pongamos un ejemplo; una operación como la paráfrasis (subrayada abajo) del referente:

[...] es que la sociedad española, entre todos, creemos dos millones de puestos de trabajo

será textual, pero, al mismo tiempo, se entenderá como interactiva, si lo que estamos considerando es explicarnos correctamente, ser deferentes hacia el oyente, ante una posible incomprensión o malinterpretación. Por consiguiente, habrá que calibrar la "predominancia" de una operación discursiva para asignarle uno u otro término. Aplicaremos el adjetivo "textual”

2 Sobre el procesamiento discursivo, véase Cortés y Camacho (2005). Sobre conexionismo, Munakata y Mccelland (2003), Perry (2010), Sloutsky (2010), French et al. (2011), McCelland (2010, 2013a, 2013b), Rasmussen y Eliasmith (2011), Rogers y McCelland, Cleeremans (2014).

${ }^{3}$ No obstante, a efectos de estudio, cabe el análisis exclusivamente textual o exclusivamente interactivo. 
a un determinado procedimiento discursivo porque sobreentenderemos que, aun presentando ambas vertientes -textual e interactiva- presentará un mayor componente textual que intersubjetivo. Por ejemplo, y ya acercándonos al objeto de nuestro artículo, que son los referentes; el hecho aséptico de referirse a una realidad externa a los participantes será textual, porque está respaldado por acciones de intelección que no afectan en gran medida a la esfera emotiva de los participantes. Por el contrario, cualquier enunciado que contenga alusiones directas o indirectas a los hablantes será interactivo, independientemente de que preexista toda una elaboración textual de procesamiento previo:

[...] porque el presidente del Gobierno, señor Rajoy, tiene que ser una persona decente y usted no lo es.

Partiendo de que la forma del discurso presenta regularidades en la linealidad de su expresión, y partiendo, también, de que un hablante pertenece a una comunidad que comparte esquemas mentales ${ }^{4}$, parece lícito suponer que los hablantes poseen unas expectativas en cuanto al orden en que las palabras se asocian, a medida que van oyendo las emisiones discursivas del hablante en la cadena hablada; expectativas según las cuales el oyente prevé mentalmente qué continúa después de las últimas palabras que está oyendo, en virtud de determinados formatos, mientras que descarta otros; en ellos se incluye su contenido explícito -lingüístico- e implícito -pragmático o discursivo-. Dicho de otro modo, cuando Pedro Sánchez va emitiendo un mensaje como:

Que están pagando 17000 millones de euros más en impuestos que hace cuatro años. Déjeme terminar que ahora es mi turno, señor Rajoy. Ahora es mi turno, señor Rajoy.

${ }^{4}$ La tipificación a que nos referimos responde a una denominación (schemas) ya usada en los años treinta por el psicólogo experimental-cognitivo (1932), cuyas teorías están aún vigentes, con las adaptaciones oportunas. Los esquemas, aplicados, en nuestro caso a procesamiento lingüístico, también reciben la denominación de frames, "escenarios" o scripts, que se pueden ampliar al discurso, en tanto que tales esquemas de actividades sustentan un conjunto de reglas de comportamiento que ofrecen la posibilidad de considerar ciertos objetivos que los interlocutores reconocen y la posibilidad de excluir otros. Para saber a qué atenerse, los hablantes cuentan en su saber colectivo con una "matriz" de una situación -a la que, como analistas, pretendemos llegar-, gracias a la cual, todos los individuos que comparten una lengua pueden adoptar papeles adecuados de manera estereotipada, socialmente aceptable, en que cada papel que se desempeña comportaría unas obligaciones y unos derechos. En la misma línea, pero con diferente nomenclatura, la Escuela de Friburgo (Berrendonner, 2008: 6: "On postule d'une part que l'exercice de la parole a pour fonction essentielle d'instaurer et de faire évoluer un ensemble de représentations extra- linguistiques publiquement partagées par les sujets parlants, ou mémoire discursive (M). Ses éléments sont appelés génériquement "objets-de-discours", quel que soit leur format cognitif (individus, classes, référents "massifs", faits, actions, espaces, instants, etc.) et la façon dont la langue les dénomme”). 
Mariano Rajoy, como oyente que tiene que descodificar e interpretar el mensaje, no esperaría el enunciado que hay subrayado porque encaja con mínimas probabilidades estadística en el esquema de lo previsible, según va procesando su mente simultáneamente al hecho de comprender y descifrar. Ello no implica que el enunciado subrayado no sea inteligible ni esté asentado en la lengua española, sino que, con toda probabilidad, conlleva un esfuerzo cognitivo adicional o sobreesfuerzo conexionista de ida y vuelta -si cabe la expresión-. De no haberse producido ese enunciado incrustado, inciso o acotación, el oyente se hubiera ahorrado algún recorrido conexionista entre nodos ${ }^{5}$. ¿Qué ha sucedido? El emisor, Pedro Sánchez, señala un hecho objetivo, ajeno a él y a Rajoy en su esfera más íntima: los impuestos que paga el contribuyente; pero, inopinadamente, empieza a hablar de otra cosa, a cambiar la naturaleza del referente; Sánchez prevé que no podrá acabar su enunciado y pasa a hacer una petición a su interlocutor Rajoy de que no lo interrumpa. Se ha producido un desplazamiento de referente, desde un tema externo (impuestos) a un tema interno (censura de uno a otro); se ha pasado del objeto al sujeto, de los impuestos a la admonición, mediante la puesta en relieve implícita de una indeseable grosería, que es un posible o real mal uso del turno de palabra. Sánchez ha pasado directamente de exponer a corregir, con justificación añadida (Ahora es mi turno, señor Rajoy). El referente ha pasado de ser algo ajeno a constituirse en un "tú y yo y nuestras relaciones". Ha ocurrido un cambio en el siguiente triángulo:

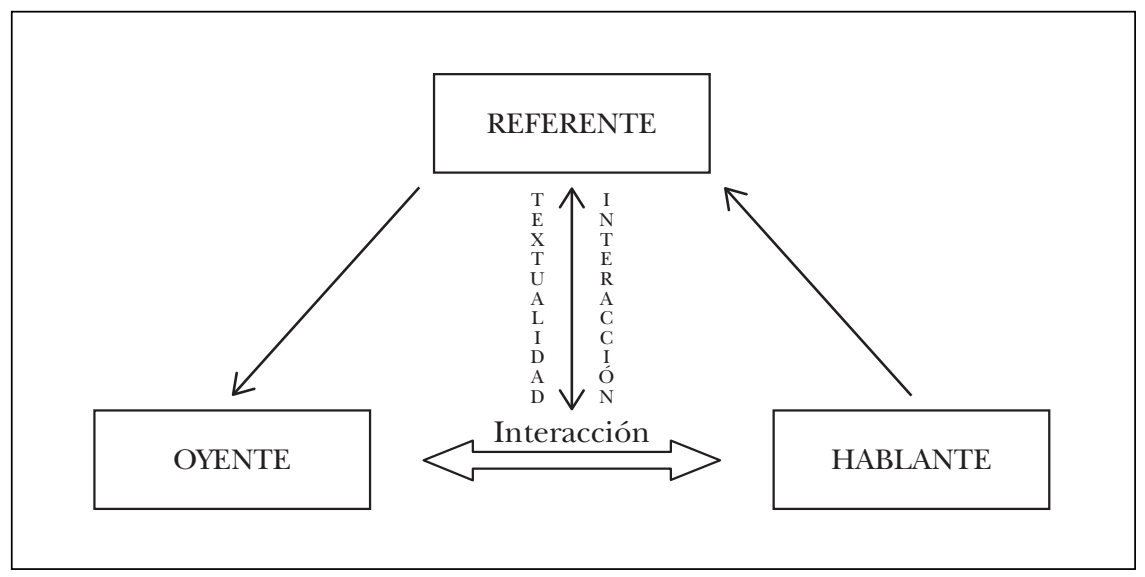

${ }^{5}$ Esto no tiene por qué implicar obligatoriamente enlentecimiento apreciable en la superficie -en las respuestas-, sino mayor número de conexiones mentales entre nodos. Al tratarse de milisegundos, el sobreesfuerzo no ha de entenderse en toda su literalidad. 
Con lo cual, la textualidad ha desaparecido, para convertirse en interacción:

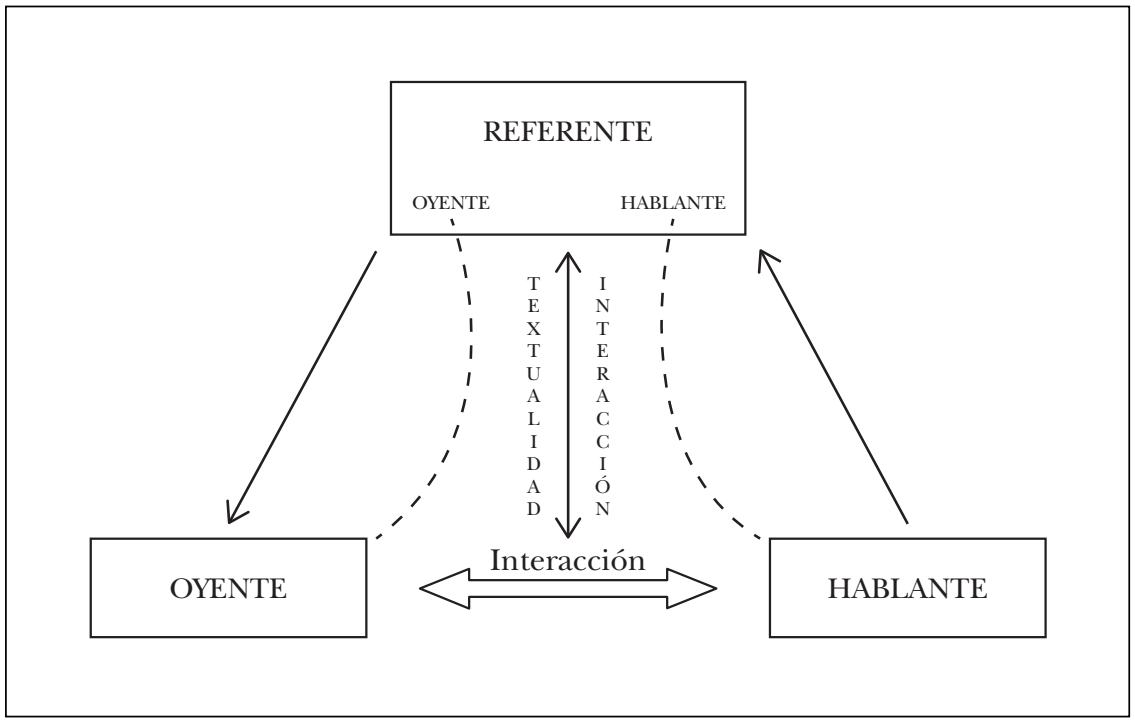

\section{LAS ESCURRIDIZAS UNIDADES PARENTÉTICAS}

\subsection{Parentéticos y saltos referenciales}

2.1.1. El criterio de la Sintaxis es y ha sido el más definitorio para identificar las unidades parentéticas; se extiende a la mayoría de idiomas ${ }^{6}$, constituyéndose en criterio transversal en una buena parte de las publicaciones pasadas y presentes. Las definiciones, con variantes, suelen adaptarse a la estructura canónica de la llevada a cabo por Bolinger (1989):

Parentheticals are clausal or subclausal units that are "wedged" in a host sentence or tagged on at the end (pág. 185).

La mayor parte de ellas caracterizan al parentético como fragmento que interrumpe la linealidad de la información, con una ruptura de su

${ }^{6}$ Aparte de las conocidísimas publicaciones anglohablantes, autores como Griffiths y Güneş (2015), para el parentético comparado entre el alemán y el turco; Bacskai-Atkari (2014), para los parentéticos en húngaro o Kan (2009), para el chino mandarín, dan testimonio del interés mundial por el tema. 
estructura sintáctica; asimismo -aunque ya estos elementos son prosódicos- presenta incisos delante y detrás de él, junto a una determinadacurva melódica que lo identifica como un todo ${ }^{7}$. Una vez suspendido el enunciado por esa segunda estructura emergente, se reanuda. Véase en el siguiente subrayado:

Mariano RajoY: [...] Y este no es un proyecto de un partido político ni de un gobierno, esto creo que lo compartimos la gran mayoría de los españoles, y yo a Europa y a Bruselas le he dedicado una parte muy importante de mi tiempo.

Nociones con términos como matriz o host (enunciado que alberga al parentético que, en nuestro ejemplo, coincide con la parte que no está subrayada) se hacen moneda común; a partir de ahí se multiplican las nomenclaturas ${ }^{8}$.

Pero la Sintaxis entraña no pocos problemas. Uno de ellos es el de la recomposición de la estructura a partir del enunciado inicial; es decir, el problema de elucidar qué relación existe entre el enunciado incrustado y el que lo contiene, qué procedimientos lo han generado (Griffiths, 2012, 2014, 2015; de Vries, 2007). Casi infinitas disquisiciones lógicas y matemáticas entre lingüísticas, provenientes, muchas de ellas, de planteamientos chomskianos (v.g. Griffiths, 2014, 2015), aparecen para solventar la cuestión. Aunque no lo consiguen totalmente.

En general, las posturas de los gramáticos fluctúan entre la consideración del parentético como estructuralmente independiente del enunciado en el que se encaja (Espinal, 1991) y su integración sintáctica como un "añadido"; así, Corver y Thiersch (2002), por ejemplo, asimilan el funcionamiento estructural de ciertos parentéticos al de los adverbios. Pero, como decíamos, al ceñirse a la identificación exclusivamente gramatical, empieza a hacerse más enrevesada la materia, pues no es evidente la diferencia entre linealidad y jerarquía, como tampoco se acaba de deslindar si se trata de elipsis o son dos estructuras ajenas, por ejemplo.

En cuanto a las formas de los parentéticos, es muy ilustrativa, por variada, la taxonomía de elementos o estructuras que nos presenta Kaltenbök (2007: 29), no exenta, tampoco, de problemas de homogeneidad en los

${ }^{7}$ Esta varía en función de cada lengua. En español, es habitual acabar el enunciado insertado con un tonema descendente.

${ }^{8}$ Mazeland (2007), parenthetical sequences; Rossari (2012), modal parentheticals; Griffiths (2015), "PVC" (parenthetical verb constructions); Brinton (2008), comment clause; Berrendonner (2008), parenthèses; Brinton (2008), comment clause; Edmonds (1973), parenthetical clauses; Espinal (1991), disjunct constituents; Griffiths (2013), parenthetical verb constructions; McCawley (1982), discontinuous constituent; Slater et al. (2015), spoken parentheticals; Schneider (2007), reduced parenthetical clauses, y una lista casi interminable, que obviamos ahora. 
criterios. Entre esas estructuras, ofrece muchas de aplicación al español ${ }^{9}$. Así, habla de estructuras parentéticas paratácticas, a las que añade proposiciones coordinadas introducidas por "con" o " $y$ "; las famosas proposiciones de comentario, comment clauses que, por cierto, se enmarañan con determinadas proposiciones adverbiales. Incluye también estructuras sin verbo (que, al menos en español, pueden formar parte de muchos de sus apartados); question tags (que, traducidas, serían preguntas finales del tipo de ¿no?, ¿verdad? o ¿no es verdad?); la confusión entre compartimentos también se observa entre las aposiciones y las denominadas por él interpolaciones preposicionales o interpolaciones adjetivales, respecto a las cláusulas apositivas/aposiciones/coordinación interpolada/constituyentes coordinantes compartidos. Asimismo, nos parece tan interesante como acertada la introducción de vocativos e interjecciones, salvo en un sentido: que son elementos que quedan fuera de la Gramática porque, realmente, pertenecen al discurso. De hecho, esos vocativos, interjecciones o "adverbios clausales" se solapan igualmente con muchos marcadores discursivos ${ }^{10}$. El autor parte de campos distintos para establecer apartados. Desde luego, para nosotros, gran parte de los marcadores discursivos tienen la capacidad de funcionar como auténticas piezas parentéticas. Los adverbios modificadores oracionales (sentence adverbials) también son, a nuestro entender, marcadores discursivos ${ }^{11}$. Con todo, uno de los intentos actuales más certeros en cuanto a la categorización sintáctica de los parentéticos ha sido ésta de Kaltenbök (2007); aunque, al haber excluido la mayoría de estructuras presentadas y haberse centrado en lo que pudiéramos llamar "parentéticos tipo", seguimos sin poder confiar en unos criterios definitivos que, además de entender el fenómeno parentético, nos ayuden a percibir mejor qué sucede realmente en la comunicación humana. Lo cierto es que no hay unidad a la hora de considerar qué es parentético y qué no es parentético, mientras sí la hay en que el criterio sintáctico es insuficiente ${ }^{12}$.

2.1.2. Por otra parte, existe, también, cierta universalidad en el tema prosódico en relación con las expresiones parentéticas, unas veces asociado a otras subdisciplinas lingüísticas, otras veces solo. Ello, porque se suele

${ }^{9}$ No así los RNR o right node rising, que quizá tengan algún punto en común con nuestras estructuras de silepsis. Tampoco las non-restrictive relative clauses coinciden con nuestras subordinadas de relativo, pues, algunas, más bien, equivalen a marcadores discursivos del tipo "como usted se puede imaginar" o "como todos sabéis".

${ }^{10}$ Más adelante haremos una breve reseña sobre esta relación entre marcador discursivo y parentético.

11 Cortés y Camacho (2005); Camacho Adarve (2007).

${ }^{12}$ La propia Brinton (2008) señala que la ausencia de compleción sintáctica no es una característica exclusiva de los parentéticos. 
atribuir a las inserciones parentéticas, como decíamos anteriormente, una curva melódica global, unitaria y propia que las hace reconocibles. Tradicionalmente, ha habido menos estudios científicos sobre la prosodia en los parentéticos que sobre otros aspectos gramaticales o semánticos, pero en los últimos años esto ha cambiado, al menos para la lengua inglesa.

Referido al español, uno de los más significativos es el estudio de Schneider (2007), quien se centra en la prosodia, en el capítulo 9, aunque apoyándose en la Gramática, Sintaxis y Pragmática. Por su parte, Dorta también toca la prosodia en términos de "focalización", aunque, como la mayoría, sólo se ocupa de los parentéticos estándar, excluyendo una amplísima parte de ellos. Y es que en un buen número de publicaciones para el inglés se llega a la conclusión de que las regularidades que se observan son aplicables solamente a un grupo de los parentéticos, pero no a todos. La prosodia, insistimos, acaba siendo nada determinante como criterio identificativo, del mismo modo que tampoco lo era el criterio gramatical reflejado en las taxonomías.

Bolinger (1989: 186) ${ }^{13}$, como ya anticipamos, había sostenido que el parentético, además de interrumpir la linealidad, respondía a una fórmula tipo, y señalaba respecto a la prosodia:

the typical parenthesis has three prosodic characteristics: it is lower in pitch than the matrix sentence, it is set off by pause(s), and it has a rising terminal.

Sin embargo eran y son muchos los autores que discrepaban de esa universalidad. Ya en el siglo XxI, por ejemplo, Wichmann (2001: 118) indica que se ha entrado en un círculo vicioso, porque todas las construcciones lingüísticas pueden ser parentéticas, si se identifica el parentético por la prosodia. Burton-Roberts (2005: 179) sostiene:

[...] In short, they represent a "disparate and problematic range of phenomena".

En otra obra, Dehé (2007: 262) concluye, para el inglés:

[...] parentheticals are marked by certain defining prosodic characteristics in speech $[\ldots]$ this paper shows that one-to-one relation of this kind doesn't exist $[\ldots]$.

Pero es más, concluye, avanzando un paso en la relación entre gramática con prosodia:

${ }^{13}$ Ya anteriormente, Crystal (1969) había relativizado el papel de la prosodia, haciéndola depender de la función, longitud y posición del parentético. 
[...] the results presented here suggest that even strong syntactic boundaries may fail to be mapped onto prosodic boundaries in actual speech [...] (pág. 282).

En la misma línea, Slater (2015: 18):

Parentheticals do not need to be marked prosodically to be parentheticals.

Si a esto añadimos que hay parentéticos que se sitúan al final o al principio del enunciado principal ${ }^{14}$ y, por consiguiente, no ofrecen ese célebre contorno entonativo único, nuevamente nos encontramos ante una salida cortada para conocer las reglas a que debemos atenernos para el esclarecimiento e identificación del parentético. Siendo así la farragosidad del concepto y, por ende, del término, nos volvemos a preguntar qué estructuras conforman las expresiones parentéticas.

Hay enunciados, decíamos, que van fluyendo sin trabas, mientras otros obstaculizan, desordenan o estancan, más o menos ligeramente, los contenidos patentes o latentes, esto es, la fluidez discursiva. Todos esos fenómenos discursivos que rompen la linealidad temática, clasificados tradicionalmente como digresiones, parecen demasiado generales y excluyen un buen número de elementos que deben estar incluidos porque "quiebran" e "innovan". Y es que -insistimos- cada lengua presenta unas estructuras ${ }^{15}$ que los hablantes prevén, porque son fijas (por eso son estructuras), mientras otras no parecen previsibles. Veamos ejemplos de ellas, a continuación.

Ante los fragmentos discursivos ${ }^{16}$ que aparecen más abajo, el segmento que contiene el giro o quiebro aparece subrayado; este que se suele constituir en un enunciado diferente. A su lado, concretamos con qué nomenclatura gramatical o discursiva se conocen, para ilustrar su heterogeneidad y labilidad:

[...] jamás comparé, ni por la imaginación se me hubiera pasado, a un terrorista con un refugiado de Siria $[\ldots] \rightarrow$ proposición coordinada

[...] luego hablaré, si tengo tiempo, de lo que creo que hay que hacer en África. $\rightarrow$ proposición subordinada

[...] hay que hablar de un presupuesto europeo, estoy de acuerdo con lo que he oído aquí, y hay que hablar de un Parlamento y un Gobierno [...]

$\rightarrow$ proposición yuxtapuesta

\footnotetext{
${ }_{14}$ Brinton (2008: 12), por ejemplo, afirma que en la posición no inicial formas tales como I think o as you know son parentéticos, sin lugar a dudas.

${ }^{15}$ Producto o reflejo de ciertos recorridos entre nodos.

${ }^{16}$ No olvidemos que son ejemplos extraídos del debate televisado por TVE el 14-12-2015 entre Pedro Sánchez y Mariano Rajoy.
} 
$[\ldots]$ Dos cosas, por favor, muy telegráficas $[\ldots] \rightarrow$ interjección o marcador discursivo

[...] es que la sociedad española, entre todos, creemos dos millones de puestos de trabajo [...] $\rightarrow$ complemento circunstancial

Y lo que tenemos que hacer es actualizarla al siglo XXI, a la España de 2015.

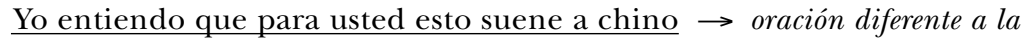
anterior

El año 2012 fue, probablemente, uno de los años más duros de la economía española $\rightarrow$ adverbio oracional, adverbio modificador oracional o marcador discursivo, según autores y corrientes

Como hemos comprobado, es muy poco operativo incluir en la casilla de los parentéticos esta mezcolanza de unidades, producto de concepciones tan diferentes como la Gramática y el discurso; con el agravante de que, a veces, se solapan: véanse, por ejemplo, algunas interjecciones (joiga!), adverbios modificadores oracionales (desgraciadamente), locuciones adverbiales (de modo ineluctable) o vocativos (señor mí) que son marcadores discursivos, con una perspectiva más amplia.

Hagamos un inciso, ahora, para exponer, someramente, que hay autores que han trabajado en los marcadores del discurso como unidades parentéticas. A finales de los años noventa, Rouchota (1998) incluyó un amplio número de los marcadores que hemos señalado arriba; fue uno de los primeros en introducir como parentéticos marcadores interactivos, como "alas" y "huh" (págs. 120-121). Tal y como señala Jucker (1998: 6):

Within speech-act theory ${ }^{17}$, the three types of parenthetical expressions considered here, i. e. sentence adverbials, parenthetical verbs and adverbial discourse connectives are analysed in similar terms.

En el siglo XxI, Traugoy y Dasher (2002) demuestran que hay algunos marcadores de cortesía en italiano (nuestros marcadores interactivos eulógicos) que han evolucionado diacrónicamente a partir de verbos y han ido adquiriendo valor de parentéticos gradualmente. Por su parte, Rossari (2004) dilucida sobre si los adverbios de actitud (marcadores discursivos) son parentéticos o no parentéticos, y llega a la conclusión de que los de actitud, a diferencia de los adverbios modales, son metadiscursivos, es decir, explican la forma de decir y no aceptan integración sintáctica; además, los modales sí se integran en el contenido semántico ${ }^{18}$ (cap. I).

\footnotetext{
${ }^{17}$ Nosotros lo extendemos a una perspectiva más amplia, discursiva.

18 Aunque no compartamos esos matices, es interesante el hecho de que ella ya marcaba una pauta en la consideración de ciertos marcadores como unidad parentética.
} 
Para finalizar y abreviar, Cuenca (2013) insiste también en lo difícil que es deslindar el marcador discursivo del marcador modal. También Brinton (2008) ha trabajado en el grado de desemantización del marcador discursivo y establece un grupo de "marcadores pragmáticos", sometidos a descategorización, sin significado referencial, con ciertos papeles funcionales (pág. 72), mientras hay otra categoría específica como parentética (cap. 11), que viene a coincidir con la definición clásica del parentético puro, si bien bajo el marbete de marcador discursivo del tipo I mean o as you know.

2.1.3. Hechas estas observaciones respecto a marcadores, hagamos ahora tabula rasa y centrémonos en estas dos nociones mencionadas antes someramente:

i) referente $\mathrm{y}$

ii) quiebro o giro.

2.1.3.1. En cuanto al referente, ya avanzamos en la introducción que las emisiones lingüístico-discursivas llevan paralelamente implícitas elementos interactivos y textuales. Lo que se oye o se lee está repleto de vestigios, tanto de lo que sucede en las mentes de oyente y hablante respecto a la conformación/descodificación lingüística del mensaje -procesamiento puramente verbal-, como del entramado de relaciones socio-afectivas entre hablantes, que no es independiente del procesamiento; la expresión se convierte en un delator desleal porque revela mucho más sobre nosotros, nuestra cosmovisión y nuestros sentimientos de lo que querríamos. Los referentes del discurso, según expusimos también, se clasificaban en predominantemente textuales y predominantemente interactivos, porque cada enunciado presentaría un cariz más textual o más interactivo en función del referente o referentes que tengan en la comunicación ${ }^{19}$. Por ejemplo, en el enunciado:

Simplemente el tiempo sólo lo necesito para decir que el Sr. Sánchez no ha explicado aquí su afirmación de que yo he recortado el derecho a las mujeres a ser madres y me parece intolerable.

consideramos que el referente principal no es el propio discurso de Rajoy, referido al tiempo de su turno y las valoraciones sobre las afirmaciones de su rival, sino que, mediante esas referencias, preponderantemente metalingüísticas, se origina un verdadero ataque al interlocutor, que es el efecto perlocutivo, por así decir, que produce; dicho de otro modo, no diríamos

${ }^{19}$ No obstante, a efectos de estudio, cabe el análisis exclusivamente textual o exclusivamente interactivo. 
que el contenido de ese enunciado tiene un referente mixto de objeto (el metadiscurso) + sujeto (la valoración subjetiva de lo que es intolerable) ${ }^{20}$ -referente, a fin de cuentas, textual e interactivo a partes iguales-, sino un referente mayormente interactivo, que da lugar a un enunciado interactivo de agresión a Sánchez.

A la inversa, un enunciado expresado por el moderador Campo Vidal como:

[...] trataremos de que los tiempos sean equivalentes, aproximadamente, y hablarán sin límites, sin pactos previos, de lo que estimen oportuno [...].

tiene como contenido o referente un objeto metadiscursivo que no arremete contra nadie, ni al contrario; tampoco toca susceptibilidades de los que debaten; por este motivo, se considerará un enunciado preeminentemente textual. Entonces, por textual entenderemos cualquier fragmento discursivo relativo a algo, un "objeto", que no afecte en gran medida a la esfera emotiva de los hablantes. Hay tantos referentes textuales como posibles temas "ajenos" a los avatares psicológicos, pero, no por ello, imposibles de esquematizar. Veamos:

- La realidad "exterior" (descripciones, exposiciones, narraciones).

- El discurso estricto o formulación discursiva, sin más implicaciones interpersonales, en todas sus variantes metalingüísticas.

- El pensamiento (silogismos, abstracciones de toda índole).

- Contenidos mixtos entre los subgrupos anteriores.

Las combinaciones anteriores pueden utilizarse, por otra parte, como apoyaturas en que realizar acercamientos o alejamientos respecto al interlocutor. En este caso, su cariz habrá cambiado y se habrán transformado en enunciados interactivos, porque estos siempre se proyectan en las relaciones que mantienen oyente y hablante.

2.1.3.2. Pasemos ahora a la segunda noción (ii), de quiebro o de giro. Si el hablante pasa, con más o menos brusquedad de la emisión de un enunciado textual a otro enunciado interactivo o viceversa, estaremos ante saltos referenciales. Serán saltos interactivos, si ha habido un desplazamiento desde temas "asépticos", es decir, del "objeto" (temas de arriba), a otros temas más personales -sujeto-, aunque se traen de manera muy indirecta. Los saltos textuales llevarán el recorrido contrario, desde la interpersonalidad al objeto.

Observemos ahora los siguientes enunciados:

${ }^{20}$ Entendiendo "sujeto" como rechazo o evaluación negativa por parte del emisor y, "objeto" como la referencia a un "decir". 
(1) Jamás comparé, ni por la imaginación se me hubiera pasado, a un terrorista con un refugiado de Siria [...]

jamás comparé (narración de hechos pasados) $\rightarrow$ Referente objeto 1

ni por la imaginación se me hubiera pasado, Quiebro o giro (justificación personal) $\rightarrow$ Referente objeto

a un terrorista con un refugiado de Siria [...] (continuación del enunciado iniciado antes del quiebro; o sea, de la narración suspendida)

$\rightarrow$ Referente objeto $1^{21}$

(2) No puede ser que nosotros compartamos la moneda euro con el resto de formaciones, o mejor dicho, estados miembros, y que en cambio no tengamos una política presupuestaria común

No puede ser que nosotros compartamos la moneda euro con el resto de formaciones (valoración de unos hechos) $\rightarrow$ Referente objeto 1

o mejor dicho, estados miembros, quiebro o giro (corrección metalingüística) $\rightarrow$ Referente objeto $1_{1}$

y que en cambio no tengamos una política presupuestaria común (continuación de la valoración de hechos) $\rightarrow$ Referente objeto 2

(3) [...] luego hablaré, si tengo tiempo, de lo que creo que hay que hacer en África

luego hablaré (aserto metalingüístico) $\rightarrow$ Referente objeto 1

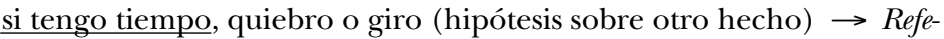
rente objeto 2

de lo que creo que hay que hacer en África $\rightarrow$ (continuación en la expresión del aserto previo) $\rightarrow$ Referente objeto 1

(4) $[\ldots]$ Dos cosas, por favor, muy telegráficas $[\ldots]$

[...] Dos cosas, (aserto metalingüístico) $\rightarrow$ Referente objeto

por favor, giro o quiebro (ruego cortés al oyente) $\rightarrow$ Referente sujeto muy telegráficas. Continuación del aserto metalingüístico previo $\rightarrow$ Referente objeto

(5) [...] hay que hablar de un presupuesto europeo, estoy de acuerdo con lo que he oído aquí, y hay que hablar de un Parlamento y un Gobierno [...]

hay que hablar de un presupuesto europeo, (aserto sobre opinión de un estado de cosas) $\rightarrow$ Referente objeto 1

estoy de acuerdo con lo que he oído aquí: Giro o quiebro (aserto empático con el interlocutor) $\rightarrow$ Referente sujeto

y hay que hablar de un Parlamento y un Gobierno (continuación del aserto anterior al giro) $\rightarrow$ Referente objeto 2

${ }^{21}$ Con todo, el mensaje es, globalmente interactivo, desde el momento en que la interpolación pretende ser una justificación del hablante ante el oyente. 
(6) [...] es que la sociedad española, entre todos, creemos dos millones de puestos de trabajo

[...] es que la sociedad española (aserto sobre una idea) $\rightarrow$ Referente objeto 1

entre todos, quiebro o giro (especificación o concreción de la idea anterior $) \rightarrow$ Referente objeto $1_{1}$

creemos $[\ldots]$ (continuación de la idea anterior a la especificación) $\rightarrow$ continuación del referente objeto 1

(7) Y lo que tenemos que hacer es actualizarla al siglo XXI, a la España de 2015. Yo entiendo que para usted esto suene a chino

Y lo que tenemos que hacer es actualizarla al siglo XXI, a la España de 2015 (aserto sobre opinión de un estado de cosas) $\rightarrow$ Referente objeto Yo entiendo que para usted esto suene a chino. Quiebro o giro (agresión indirecta en forma de valoración) $\rightarrow$ Referente sujeto

(8) El año 2012 fue, probablemente, uno de los años más duros de la economía española

El año 2012 fue (narración de hechos pasados) $\rightarrow$ Referente objeto 1 probablemente, Quiebro o giro (aserto sobre valores de verdad que indica duda) $\rightarrow$ Referente objeto 2

uno de los años más duros de la economía española (continuación de la narración) $\rightarrow$ continuación del referente objeto 1

Todos los referentes apuntan al objeto o al sujeto, indefectiblemente: al menos podemos contar con una característica, un desdoblamiento primario al que se adapta cualquier enunciado. Pero, además, todos tienen otro elemento en común: el referente y el giro. Fijémonos en que la información "inesperada" (el quiebro o giro), siempre apunta a un referente distinto:

i) desde un objeto a un sujeto;

ii) en el interior del mismo objeto o sujeto ${ }^{22}$ que, en otras nomenclaturas, es el giro temático hacia un subtema;

iii) transición desde un objeto a otro objeto diferente $\mathrm{e}^{23}, \mathrm{y}$

iv) el giro de un sujeto a un objeto.

En todos los casos, ha habido un salto referencial con diferentes niveles de brusquedad.

\footnotetext{
${ }^{22}$ Objeto $_{1}$, objeto $_{2} \ldots$ objeto $_{n}$ o sujeto $_{1}$, sujeto $_{2} \ldots$ sujeto $_{n}$

${ }^{23}$ Objeto $_{1}$, objeto $_{2} \ldots$ objeto $_{\mathrm{n}}$
} 
Por otra parte, observamos que muchas de las expresiones subrayadas están insertas en el centro del enunciado y, verdaderamente, se delimitan por comas o puntos, como representaciones de pausas en la modalidad oral $^{24}$ : ese el parentético: un subgrupo dentro de los enunciados o actos que conforman los saltos referenciales. Podemos, entonces, afirmar, que los $p a$ rentéticos constituyen un subgrupo dentro del fenómeno mucho más amplio de los saltos referenciales, si reparamos en que también hay enunciados que "saltan" al principio o al final y no tienen las pausas pretendidamente preceptivas.

\section{Clasificación de los SAltos REFERENCiales}

Los criterios en que nos basamos son varios y excluyentes. Por motivos de extensión, iremos enumerándolos y, en lugar de teorizar, solamente los ejemplificaremos, salvo en los casos en que quepa cierta imprecisión o sea estrictamente necesario

\subsection{Por su referente}

A. Según su predominancia referencial: textuales/interactivos y pseudotextuales/pseudointeractivos.

a) Saltos referenciales textuales (desplazamiento referencial desde un enunciado interactivo a un enunciado textual):

(9) [...] No, no soy displicente (salto textual). Porque lo hacemos en Cataluña, lo estamos haciendo en la Comunidad Valenciana, en Murcia...

b) Saltos referenciales interactivos (desplazamiento referencial desde un enunciado textual hasta otro interactivo):

(10) Libramos a España del rescate, (salto interactivo) mal que le pese a

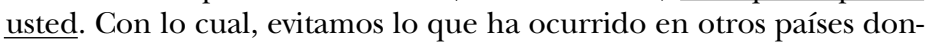
de han bajado las pensiones un $20 \%$ [...]

c) Saltos referenciales pseudotextuales (aparentemente son textuales, pero su predominancia es la otra. En el fondo, son saltos interactivos):

(11) $[\ldots]$ aunque luego dijo que, quizá, se había equivocado y que había que reformar ese artículo 135. (salto pseudotextual) Quizá hoy, pueda aclararnos este asunto. Creo que la Constitución se puede reformar

${ }^{24}$ No entraremos ahora en los vestigios que de la oralidad queden en la escritura. 
Aquí, el salto referencial se realizaría desde un referente-objeto (narración de unos hechos en boca de otro) a otro referente-objeto (en este caso, metalingüístico), pero solo en apariencia, porque, en realidad, es un agresión que pretende dejar en evidencia al interlocutor, demostrando que ha caído en contradicción; de ahí que sea un salto interactivo, realmente.

d) Saltos referenciales pseudointeractivos (aparentemente son interactivos, pero su predominancia es la otra -en el fondo, son saltos textuales-):

(12) Son datos oficiales, Sr. Sánchez (salto pseudointeractivo). Si no le gustan, lo siento mucho [...]

El salto "interactivo" subrayado no es tal. El emisor no está comunicando nada sobre las apetencias y complacencias del receptor ni propias. Habla sobre la contundencia inalterable de los datos. Y esto es un referente textual.

B. Por el grado de literalidad enunciativa: directos/indirectos

a) Saltos referenciales directos o explícitos (lo que se comunica es explícito $\mathrm{y}$ admite pocas interpretaciones):

(13) [...] que es nuestro mercado, nuestros aliados naturales. (salto directo) Eso es lo que quiero plantearles yo. En ese escenario cada vez más complejo, en un continente como Europa [...]

(14) $[\ldots]$ De eso no se va a recuperar usted nunca. (salto directo) $\underline{\text { Si usted }}$ tiene algo contra mí, lléveme al juzgado, pero no estoy dispuesto a aceptarle nada sobre cuestiones de honradez [...]

b) Saltos referenciales indirectos, deducibles o implicitos

(15) $[\ldots]$ he estado en la entrega de los premios de asociaciones que peleaban contra la violencia de género (salto interactivo indirecto) ¿̇a qué juega usted?

Tampoco parece necesario explicar ${ }^{25}$ que la transmisión del mensaje de Rajoy a Sánchez habría resultado un fracaso, si Rajoy hubiera descodificado las palabras subrayadas literalmente.

C. Por la foricidad textual enunciativa: prospectivos/retrospectivos/lineales

a) Saltos referenciales prospectivos. Estos saltos son el resultado de la insatisfacción del emisor, quien prevé que su enunciado pudiera no

${ }^{25}$ Desde la Teoría de los Actos de Habla, estos asuntos se conocen sobradamente. 
ser todo lo eficiente que debiera. Por eso es habitual que incluyan algún verbo de habla -aunque no es obligado-. El hablante introduce otro enunciado nuevo, como avanzadilla de su posible efecto no deseado. Aclarar posibles ininteligibilidades, prevenir agresiones dialécticas o personales, evitar groserías o actitudes que pudieran resultar negativas o, al contrario, usar estos saltos como ataque previo son algunos ejemplos de las funciones de estos saltos... son enunciados que se anticipan, y por ello se hallan en la órbita de la reformulación con finalidad de reparación o restauración previa, tanto si se enuncian con fines positivos como hostiles.

(16) (Salto prospectivo) Voy a contestarle a tres o cuatro de algunas de las curiosas afirmaciones que he oído. Oírle hablar a usted del sistema de pensiones, cuando el Partido Socialista fue el único partido [...]

b) Saltos referenciales retrospectivos. Es de aplicación todo lo que se ha dicho en los saltos prospectivos. La reformulación reparadora existe igualmente, pero a posteriori:

(17) [...] tenemos la amenaza del terrorismo yihadista, tenemos una presión inmigratoria muy importante en Europa. Y tenemos presente también las relaciones con Latinoamérica, que es nuestro mercado, nuestros aliados naturales. (salto retrospectivo) Eso es lo que quiero plantearles yo.

c) Saltos referenciales lineales. Ni se adelanta ningún contenido ni se hace mención a nada de lo dicho antes:

(18) Yo defiendo la España unida, una España diversa y en convivencia.

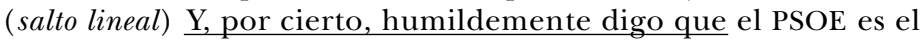
mejor garante de la unidad de España

\subsection{Por su forma}

a) Saltos referenciales abruptos (extratextuales o extrainteractivos). Esta clasificación coincide con las nociones ya explicadas en lo concerniente a saltos abruptos que van de lo textual (objeto) a lo interactivo (sujeto) o a la inversa.

(19) Cristóbal Montoro dijo aquello de: "Que se hunda España, que ya vendremos a rescatarla”. (salto interactivo) ¡Menudo patriota!, Pero le voy a recordar algunas fechas $[\ldots]$

b) Saltos referenciales suaves (intratextuales o intrasubjetivos). En el anterior apartado, hemos ejemplificado el quiebro "insospechado" (desde 
el punto de vista del procesamiento, recordemos). Ahora, ese giro se produce con menor brusquedad, sin perjuicio de poderse establecer, a su vez, una escala entre dos polos de suavidad enunciativoreferencial. El salto, ahora se experimenta desde un objeto/sujeto 1 a otro objeto/sujeto $2^{26}$; también hemos mencionado los giros de objeto $_{1} /$ sujeto $_{1}$ a objeto $_{2} /$ sujeto $_{2}$. En realidad, el primer enunciado, si es textual, gira a otro también textual, en virtud de operaciones lógico-lingüísticas ${ }^{27}$ expansivas del tipo hipótesis, aserción, negación, justificación, consecuencia, refuerzo o adición (argumentativa o no), contraargumentación, conclusión, restricción, ejemplificación, concreción, paráfrasis, rectificación, relieve o insistencia, contradicción, contraste, resumen, generalización, ordenación temporal, espacial o adición continuadora, paráfrasis... que no repercutan en las relaciones entre los hablantes, decíamos.

(20) Y pueden contratar a cualquiera de las dos personas que hay aquí, $\mathrm{o}$ a un tercero. (Salto intratextual de objeto a objeto $_{1} \rightarrow$ especificación o concreción parafrástica) Así de rotundo, así de trascendental

(21) ¿a qué juega usted? (salto intrasubjetivo $\rightarrow$ especificación que funciona en el ámbito de lo personal) Es decir, ¿por qué quiere confrontar conmigo en estos temas de violencia de género si todos estamos de acuerdo que es un disparate todas esas...

c) Saltos referenciales con marcas de transición. Todas las clases de saltos aquí clasificados pueden estar introducidos por elementos que marcan ese desplazamiento referencial repentino; por ejemplo, un marcador discursivo que no suponga cambio alguno en su contenido referencial ${ }^{28}$ y, por ende, sin posible valor parentético (del tipo de los retardatarios). También pueden desempeñar ese papel las repeticiones, e incluso simples balbuceos y similares:

(22) Vamos a unir los trabajadores autónomos a las cotizaciones sociales que sean adecuadas a los rendimientos netos de sus ingresos al mes.

${ }^{26}$ En otras nomenclaturas, es un giro temático hacia subtema.

27 Se han tratado como digresiones suaves o bruscas.

28 No todos los marcadores discursivos pueden ser parentéticos, ni tienen el mismo grado de desemantización o discursivización. Tampoco tienen por qué suponer, en sí mismos, saltos referenciales, como muchos de los marcadores textuales de apertura y cierre y otro buen número de los de desarrollo -cfr. Cortés y Camacho (2005)-. Los considerados por nosotros "saltos" conservan gran parte o todo su contenido referencial, aunque ésta es una cuestión secundaria a la hora de determinar si una unidad es o no marcador del discurso, porque la perspectiva de análisis no es gramatical o semántica, sino discursiva, y los parámetros, otros. Es interesante la obra de Aijmer $(1997,2003)$ a este respecto. 
Vamos a unir, (salto con marca de transición, que es la repetición previa) y termino con esto, señor, vamos a unir, señor Rajoy...

La repetición, como vemos en (22), sirve para centrarse con más facilidad de procesamiento en la enumeración de las intenciones de acción del hablante. Mientras en (23, abajo), no se vuelve, sino que se salta hacia adelante, vía marcadores textuales.

(23) No viene reconocido en la Constitución Española los principios básicos de la financiación autonómica, (salto con marca de transición consistente en marcador textual digresivo) que, por cierto usted lleva incumpliendo su actualización desde hace dos años.

d) Saltos referenciales sin marcas de transición

(24) [...] será el único de esta campaña electoral. (salto sin marcas) $\underline{\text { Único }}$ y para todos. Antes de las elecciones del 20 de diciembre

e) Saltos referenciales dependientes. Forman parte indivisible de la unidad discursiva en la que se produce; por eso suelen ser saltos suaves, a pesar de pasar de lo textual a lo interactivo o al contrario en el mismo enunciado:

(25) Causa sonrojo cuando no indignación (salto textual-desde el principio interactivo del enunciado-indivisible del mismo) recordar algunas de las cosas que han pasado durante estos últimos cuatro años [...]

f) Saltos referenciales independientes. Aquí tendrían su lugar los parentéticos tradicionales:

(26) $[\ldots]$ antes simplemente quisiera señalar cuatro falsedades que ha dicho el Sr. Sánchez -( salto independiente) sólo cuatro porque no me ha dado tiempo a tomar nota de lo que ha dicho-: la primera es que yo me opuse a aceptar refugiados en España.

\subsection{Por su repercusión socioafectiva}

En función de que el mensaje latente o explícito comunicado por el hablante, sea descortés, afable o indiferente para el oyente, tendremos uno u otro subgrupo de saltos. En este apartado el hecho de que el enunciado sea más textual o menos interactivo es secundario, porque lo relevante es exclusivamente la interacción; es decir, cómo funciona ese enunciado en el plano de las relaciones humanas. El etiquetado, aunque se pudiera entender como pseudotextual o pseudointeractivo, en realidad no cabe, pues aquí esa cuestión no nos interesa. 
a) Saltos referenciales interactivos antipáticos o negativos

(27) Si ha bajado más de 15 puntos. (salto interactivo antipático) Por favor, no mienta.

b) Saltos referenciales interactivos empáticos o positivos. Gran parte de los saltos que hemos entendido como textuales tienen como cometido hacer más fácil la intelección del mensaje al oyente con las múltiples operaciones lógico-lingüísticas. Con este criterio de análisis, esos posibles saltos con correcciones, ejemplificaciones, concreciones, etc. -reformulaciones, a fin de cuentas- serán empáticos, aunque no tan evidentes o predominantes en su repercusión social, como los que aluden más directamente al oyente.

(28) Vamos a hablar, si les parece, de lo que yo resumo como España en el mundo.

c) Saltos referenciales apáticos o neutros. Son desafectos a las emociones de los participantes y suelen coincidir con los textuales más puros, v. gr. metadiscursivos:

(29) [...] nos estamos jugando en estas elecciones el futuro de España en los próximos cuatro años. (Salto apático) Vamos a comenzar con un minuto.

\subsection{Por su distribución en el discurso}

a) Saltos referenciales iniciales. Que no tienen por qué ser prospectivos:

(30) (Salto inicial) Yo abro... Ante todo una firme convicción. Yo defiendo $[\ldots]$

b) Saltos referenciales medios. También coinciden con los parentéticos, si son, a su vez, aislados:

(31) Son las diputaciones las que les dotan de los servicios públicos fundamentales, (salto medio) y coincido con el señor Sánchez, que quien quiere suprimirlo es porque no conoce la realidad española.

c) Saltos referenciales finales:

(32) No me dedico a la política por dinero, señor Sánchez, (salto final) y usted lo sabe.

d) Saltos referenciales aislados o únicos. Conviene distinguir este tipo de saltos de los saltos independientes que no están ensamblados (cfr. 
4.2.6), pues, aunque coincidan, no lo hacen en virtud del mismo criterio. En el caso de los saltos independientes, se hace concluyente el hecho de poder constituir una unidad discursiva (enunciado, acto o microacto), mientras los "aislados" lo son porque no trenzan su estructura con otros saltos referenciales independientes:

(33) $[\ldots]$ ¿No ha visto lo que le ha pasado al señor Tsipras en Grecia? (salto único o aislado). Debería tomar nota.

e) Saltos referenciales entrelazados. La misma observación del punto anterior ha de hacerse respecto a los saltos dependientes (cfr. 4.2.5):

(34) [...] Déjeme leerle, (salto 1 entrelazado), señor Rajoy, (salto 1 entrelazado de vuelta, textual) algo que dijo usted hace cuatro años en este debate. (salto 2 entrelazado intratextual) Tirando de hemeroteca, ( salto 3 entrelazado intratextual) porque a usted le gusta tirar de mi hemeroteca. (salto 5 entrelazado de vuelta, intratextual). Usted dijo lo siguiente $[\ldots]$

f) Saltos referenciales monológicos. Cualquier ejemplo anterior es válido.

g) Saltos referenciales dialógicos:

PEDRo SÁnChez: [...] Porque a lo mejor es un político del siglo pasado. Pero le digo una cosa, Sr. Rajoy. Reformar la Constitución significará revitalizar nuestra democracia, nuestra convivencia territorial y también la cohesión social.

(35) Mariano Rajoy: (Salto dialógico, de lo anterior textual a lo interactivo) $\underline{\mathrm{No}}$ sé de qué siglo soy yo, pero usted no ha sido ni siquiera concejal. Y sus conocimientos... ¿ ¿Ha tomado usted alguna decisión?

\section{Peculiaridades de los Saltos Referenciales en el debate político}

Sintetizando mucho, los rasgos identificadores de este debate político, en cuanto a saltos referenciales son los siguientes:

- Profusión de saltos textuales metadiscursivos apáticos o neutros, por parte del moderador. Ello es consustancial con el encorsetamiento del género y con su función: velar por que los políticos se ajusten al formato textual genuino en turnos de palabra, temas, contención verbal, etc. Veamos algunas muestras de las intervenciones de Campo Vidal:

(36) Última intervención para cerrar este bloque (salto suave intratextual) Pasamos a hablar del Estado del Bienestar 
(37) Nosotros simplemente ordenaremos los temas, haremos sugerencias a través de nuestras preguntas [...]

- Los saltos textuales del sujeto al objeto suelen tratar de política, por razones obvias.

- Baja frecuencia de aparición de saltos empáticos por parte de los oponentes dialécticos, lo que implica abundancia de saltos antipáticos. Estos, a su vez, presentan muy variadas formas:

i) El insulto directo. Las alusiones:

(38) Hay que tener un poco de nivel a la hora de utilizar los argumentos.

ii) El contenido indirecto mediante saltos deducibles -antipáticos-, que, también se materializan de diversas maneras ${ }^{29}$ :

a) Utilizando la propia realidad como arma arrojadiza. Unas veces los hechos hablan por sí mismos:

(39) usted ha permitido que en la sede de la calle Génova del Partido Popular, rehabilitada con dinero de B de Bárcenas, señor Rajoy, se haya destruido el ordenador a martillazos de Luis Bárcenas ante el requerimiento de los jueces.

Otras veces suelen ser hechos que en su naturaleza no son hostiles, pero sí en contexto, al ser socialmente denostados:

(40) [...] usted envió un mensaje al Sr. Bárcenas diciendo aquello de "estemos tranquilos, sé fuerte, Luis" [...]

b) Utilizando el metadiscurso:

(41) ¿Me deja terminar, señor Rajoy? Si no, va a hablar usted solo. Esto es un debate, no es un monólogo, señor Rajoy. $¿$ ¿Me deja terminar?

c) Empleando saltos interactivos, a partir de saltos textuales adjetivados; es decir, empleando saltos referenciales pseudotextuales:

(42) [...] la afirmación ruiz, ruin, mezquina y miserable que ha hecho usted hoy aquí $[\ldots]$

29 Ahora, cada vez que sea posible, vamos a obviar el enunciado en que se origina el salto, por cuestiones de economía. 
(43) Entonces, en aquel momento, el ministro De Guindos dijo aquello del mercado, decía, (salto antipático) ¿̇se acuerda? $[\ldots]$

d) Afianzando los propios argumentos con supuestas autoridades que refrendan lo dicho, para atacar con más encono:

(44) [...] Y además, estamos pagando también el fondo los proveedores. (Salto intratextual) Que todo el mundo lo sabe, en materia sanitaria.

e) Empleando lenguaje figurado (ironía, metáforas...):

(45) Tiene que mirar bien, usted tiene un problema en los ojos y le dificulta la visión.

(46) Moderador: Señor Rajoy, tiempo para usted

MARIano Rajoy: (Salto interactivo) Hasta aquí hemos llegado, señor Sánchez. Mire, yo soy una persona... Primero, si usted creía que yo tenía que haber dimitido y no era digno de ser.

\section{CONCLUSión}

Las características que hemos atribuido a los saltos referenciales, decíamos, eran excluyentes en su análisis, pero, aparte de exposiciones didácticas, en la comunicación real concurren simultáneamente ${ }^{30}$. Vamos a especificarlo, para que sirva de apostilla a todo el cuerpo teórico desarrollado, en forma de tabla donde se recogen todos los ejemplos con que hemos ido ilustrando nuestras impresiones. Algunos números de ejemplo no aparecen. Ello se debe a que los hemos obviado porque en el cuerpo del texto no aparecían los dos miembros del salto referencial, sino solo el salto directamente. El número que aparece a la izquierda, en la tabla, corresponde al orden de aparición del salto en el artículo, de manera que habrá que ir comparando.

En el número 34 hay incluidos varios saltos; sin embargo, sólo se refleja el análisis del primero, porque sólo nos interesa resaltar el hecho del entrelazamiento entre ellos.

${ }^{30}$ Tal y como sucede con la textualidad y la interacción. 


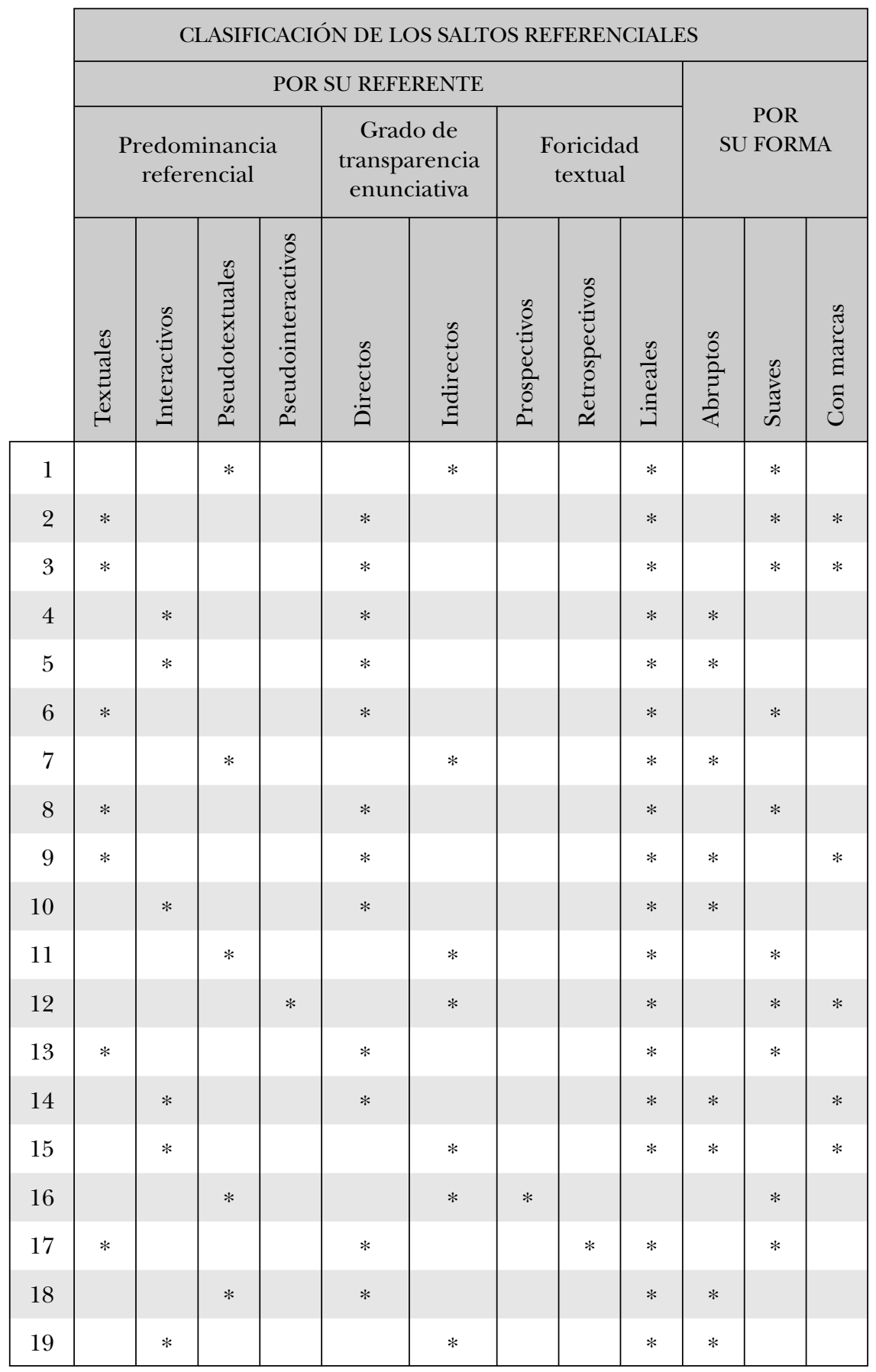




\begin{tabular}{|c|c|c|c|c|c|c|c|c|c|c|c|c|}
\hline \multicolumn{13}{|c|}{ CLASIFICACIÓN DE LOS SALTOS REFERENCIALES } \\
\hline \multicolumn{3}{|c|}{$\begin{array}{c}\text { POR } \\
\text { SU FORMA } \\
\quad(\text { cont. })\end{array}$} & \multicolumn{3}{|c|}{$\begin{array}{c}\text { POR SU } \\
\text { REPERCUSIÓN } \\
\text { SOCIOAFECTIVA }\end{array}$} & \multicolumn{7}{|c|}{$\begin{array}{l}\text { POR SU DISTRIBUCIÓN } \\
\text { EN EL DISCURSO }\end{array}$} \\
\hline 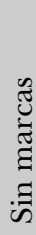 & 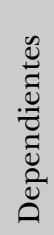 & $\begin{array}{l}y \\
z \\
z \\
z\end{array}$ & 苞 & 胥 & 苞 & 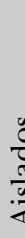 & 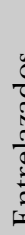 & 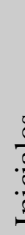 & & & & $\begin{array}{l}0 \\
.0 \\
0 \\
\frac{0}{0} \\
.07 \\
0\end{array}$ \\
\hline \multirow[t]{3}{*}{$*$} & & $*$ & & & $*$ & 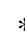 & & & & & & \\
\hline & & $*$ & & & * & : & & & & & & \\
\hline & & * & & & * & * & & & & & & \\
\hline * & & * & * & & & : & & & & & & \\
\hline$*$ & & $*$ & * & & & * & & & & & & \\
\hline \multirow[t]{2}{*}{$*$} & & * & & & * & $x$ & & & & & & \\
\hline & & * & & * & & $y$ & & & & & & \\
\hline \multirow[t]{2}{*}{$*$} & & * & & & * & $*$ & & & & & & \\
\hline & & $*$ & & * & & $y$ & & & & & & \\
\hline$*$ & & * & & * & & * & & & & & & \\
\hline \multirow[t]{2}{*}{$*$} & & $*$ & & * & & y & & & & & & \\
\hline & & $*$ & & * & & $*$ & & & & & & $*$ \\
\hline \multirow[t]{3}{*}{$*$} & & $*$ & & & * & * & & & & & & \\
\hline & & * & & * & & $*$ & & & & & & \\
\hline & & * & & * & & * & & & & & & \\
\hline \multirow[t]{2}{*}{$*$} & & $*$ & & * & & $*$ & & & & & & \\
\hline & & * & & & * & * & & & & & & \\
\hline \multirow[t]{2}{*}{$*$} & $*$ & & & & * & * & & & & & & \\
\hline & $*$ & * & & * & & $=$ & & & & & & \\
\hline
\end{tabular}




\begin{tabular}{|c|c|c|c|c|c|c|c|c|c|c|c|c|}
\hline & \multicolumn{12}{|c|}{ CLASIFICACIÓN DE LOS SALTOS REFERENCIALES } \\
\hline & \multicolumn{9}{|c|}{ POR SU REFERENTE } & \multirow{2}{*}{\multicolumn{3}{|c|}{$\begin{array}{c}\text { POR } \\
\text { SU FORMA }\end{array}$}} \\
\hline & \multicolumn{4}{|c|}{$\begin{array}{l}\text { Predominancia } \\
\text { referencial }\end{array}$} & \multicolumn{2}{|c|}{$\begin{array}{c}\text { Grado de } \\
\text { transparencia } \\
\text { enunciativa }\end{array}$} & \multicolumn{3}{|c|}{$\begin{array}{c}\text { Foricidad } \\
\text { textual }\end{array}$} & & & \\
\hline & & 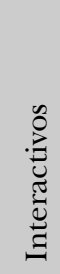 & 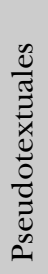 & 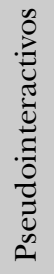 & $\begin{array}{l}0 \\
0 \\
0 \\
0 \\
0 \\
0\end{array}$ & 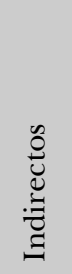 & 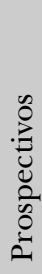 & 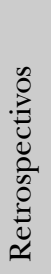 & $\underbrace{\frac{\tilde{U}}{\tilde{U}}}_{0}$ & $\frac{0}{0}$ & $\stackrel{0}{\tilde{u}}$ & 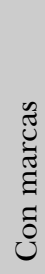 \\
\hline 20 & $*$ & & & & * & & & & * & & * & \\
\hline 21 & & * & & & & * & * & & $*$ & & * & $*$ \\
\hline 22 & * & & & & * & & & & * & & * & * \\
\hline 23 & & * & & & * & & & & * & * & & * \\
\hline 24 & $*$ & & & & $*$ & & & & $*$ & & * & \\
\hline 25 & $*$ & & & & $*$ & & & & $*$ & & * & \\
\hline 26 & $*$ & & & & $*$ & & & & $*$ & & $*$ & \\
\hline 27 & & $*$ & & & $*$ & & & & $*$ & $*$ & & \\
\hline 28 & & $*$ & & & $*$ & & & & $*$ & $*$ & & $*$ \\
\hline 29 & $*$ & & & & * & & & & * & & $*$ & \\
\hline 30 & $*$ & & & & * & & & & $*$ & & * & \\
\hline 31 & & $*$ & & & $*$ & & & & $*$ & $*$ & & $*$ \\
\hline 32 & & & $*$ & & & $*$ & & & * & * & & $*$ \\
\hline 33 & & & $*$ & & & $*$ & & & $*$ & $*$ & & \\
\hline 34 & & $*$ & & & $*$ & & & & $*$ & $*$ & & \\
\hline 35 & & & $*$ & & & $*$ & & & $*$ & * & & $*$ \\
\hline 36 & $*$ & & & & $*$ & & & & $*$ & & $*$ & \\
\hline 43 & & & $*$ & & & $*$ & & & $*$ & & $*$ & \\
\hline 44 & & & $*$ & & & $*$ & & & $*$ & $*$ & & \\
\hline 46 & & $*$ & & & & $*$ & & & $*$ & & & $*$ \\
\hline
\end{tabular}




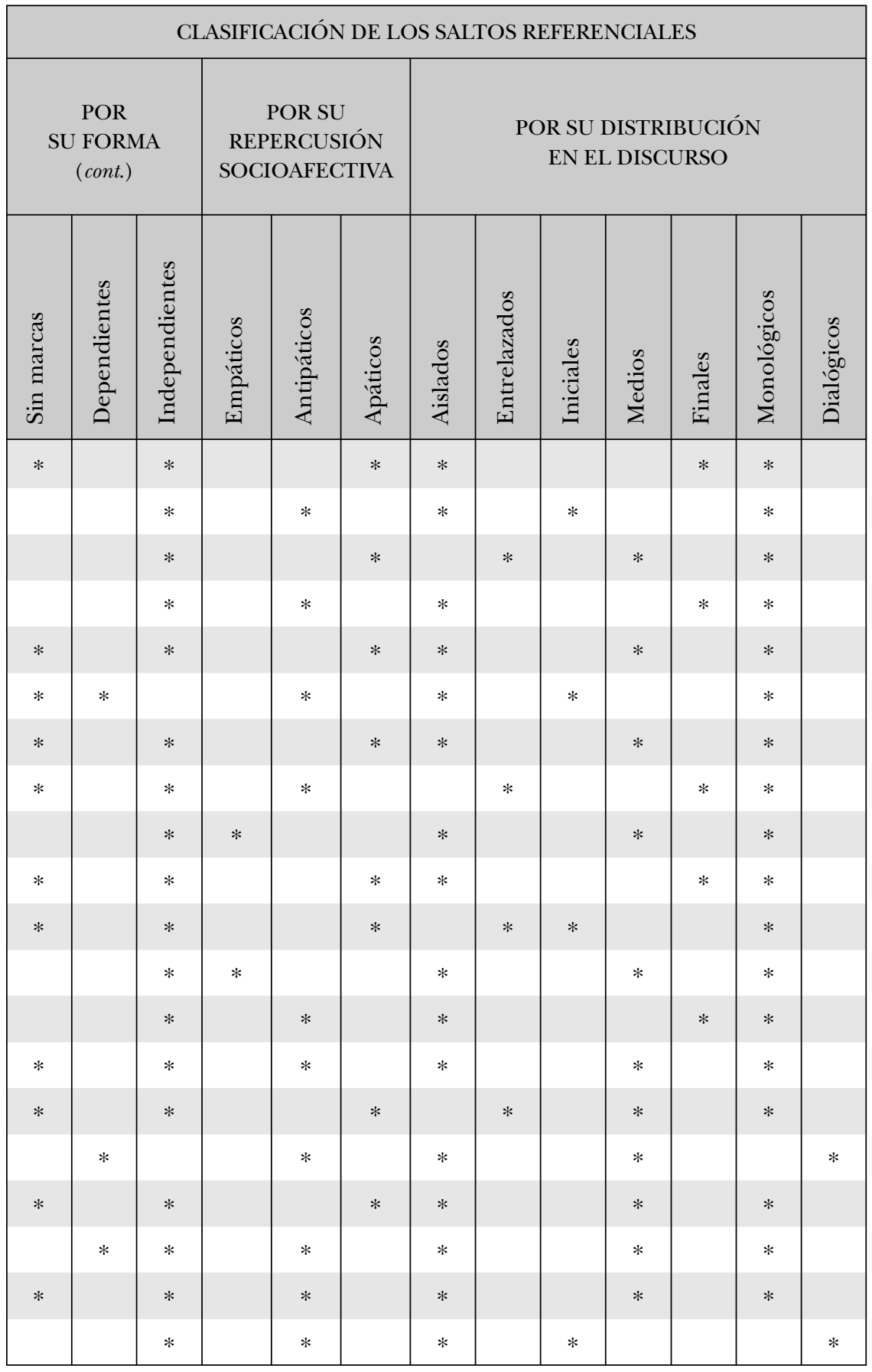




\section{BIBLIOGRAFÍA}

AjJmer, K. (1997): "I think - an English modal particle", en T. Swan y O. Jansen Westvik (eds.), Modality in the Germanic Languages, Berlín, Mouton de Gruyter, págs. 1-48.

- (2013): "Analysing modal adverbs as modal particles and discourse markers", en L. Degand et al. (eds.), Discourse markers and modal particles: categorization and description, Ámsterdam, John Benjamins, págs. 89-106.

BACSKAI-ATKARI, J. (2014): "A komparatív parentetikus tagmondatok bal perifériája. [The left periphery of comparative parenthetical clauses]", Nyelvtudományi Közlemények, 110, págs. 297-318.

Barlett, F. C. (1932): Remembering: An Experimental and Social Study, Cambridge, Cambridge University Press.

Berrendonner, A. (2008): "Pour une praxéologie des parenthèses", Verbum, XXX, 1, págs. 6-23.

BOLINGER, D. (1989): Intonation and its uses: melody in grammar and discourse, Londres, Edward Arnold.

BRINTON, L. J. (2008): The comment clause in English: Syntactic origins and pragmatic development, Cambridge, Cambridge University Press.

Camacho Adarve, M. M. (2001): "La repetición en el discurso oral", Tonos Digital: Revista Electrónica de Estudios Filológicos, 2, págs. 277-288.

- (2006): "El discurso, texto e interacción”, en Análisis del discurso: lengua, cultura, valores. Actas del I Congreso Internacional, Madrid, Arco/Libros, págs. 277288.

- (2007): "Los géneros en el discurso oral español”, Espéculo. Revista Electrónica de la UCM, 37.

Cleeremans, A. (2014): "Connecting Conscious and Unconscious Processing”, Cognitive Science, 38, págs. 1286-1315.

CortÉs, L. y CAMACHO, M. M. (2005): Unidades de segmentación y marcadores del discurso, Madrid, Arco/Libros.

CRIstal, D. (1969): Prosodic Systems and Intonation in English, Cambridge, Cambridge University Press.

Cuenca, M. J. (2013): "The fuzzy boundaries between discourse marking and modal marking”, en L. Degand, D. Liesbeth, B. Cornillie y P. Pietrandrea (eds.), Discourse Markers and Modal Particles. Categorization and description, Ámsterdam, John Benjamins, págs. 181-216.

DeHÉ, N. (2007): "The relation between syntactic and prosodic parenthesis", en N. Dehé e Y. Kavalova (eds.), Parentheticals, Ámsterdam, John Benjamins, págs. 261-284.

DORTA, J. (2008): "La focalización prosódica: funcionalidad en los niveles lingüístico y pragmático”, en Estudios de Fonética Experimental, XVII, págs. 105-138. 
Emonds, J. (1973): "Parenthetical clauses", en C. Corum, T. C. Smith-Stark y A. Weiser (eds.), You Take the High Node and I'll Take the Low Node, Chicago, Chicago Linguistic Society, págs. 333-347.

EsPINAL, M. T. (1991): “The representation of disjunct constituents", Language, 67, págs. 726-762.

FRENCH, R. M. et al. (2011): "TRACX: A recognition-based connectionist framework for sequence segmentation and chunk extraction", Psychological Review, 118 (4), págs. 614-636.

Griffiths, J. (2015): "Parenthetical verb constructions, fragment answers, and constituent modification", en Natural Language \& Linguistic Theory, 33 (1), págs. 191-229.

GrIFFITHS, J. y GÜNEŞ, G. (2015): "Ki issues in Turkish: Parenthetical coordination and adjunction", en M. Kluck et al. (eds.), Parenthesis and Ellipsis: Cross-Linguistic and Theoretical Perspectives, Berlín, Mouton de Gruyter, págs. 173-217.

Jucker, A. y Ziv, Y. (1998): "Discourse markers: Introduction”, en A. Jucker e Y. Ziv (eds.), Discourse Markers: Description and Theory, Ámsterdam, John Benjamins, págs. 1-12.

Kaltenböck, G. (2007): "Spoken parenthetical clauses in English. A taxonomy", en N. Dehé y G. Kavalova (eds.), Parentheticals, Ámsterdam/Filadelfia, John Benjamins, págs. 25-52.

KAN, S. (2009): "Multiple focus in Mandarin Chinese”, Lingua, 121, págs. 18901905.

Mazeland, H. (2007): "Parenthetical sequences", Journal of Pragmatics, 39, págs. 1816-1869.

McCanley, J. D. (1982): "Parentheticals and discontinuous constituent structure", Linguistic Inquiry, 13, págs. 91-106.

MCClelland, J. L. (2013a): "Integrating probabilistic models of perception and interactive neural networks: A historical and tutorial review", Frontiers in Psychology, 4, <http://psych.stanford.edu/ jlm/papers/McClelland13Prob ModsInteractiveNNs.pdf $>$.

- (2013b): "Incorporating rapid neocortical learning of new schema-consistent information into complementary learning systems theory", Journal of Experimental Psychology: General, 142 (4), págs. 1190-1210.

— et al. (2010): "Letting structure emerge: Connectionist and dynamical systems approaches to cognition”, Trends in Cognitive Science, 14, págs. 348-356.

Munakata, Y. y Mcclelland, J. L. (2003): "Connectionist models of development", Developmental Science, 6 (4), págs. 413-429.

Murphy, L. (1993): "Discourse markers and sentential syntax", Studies in the Linguistic Sciences, 23, págs. 163-167.

PERRY, C. et al. (2010): "Beyond single syllables: large-scale modeling of reading aloud with the Connectionist Dual Process (CDP++) model", Cognitive Psychology, 61 (2), págs. 106-151.

Rasmussen, D. y Eliasmith, C. (2011): "A neural model of rule generation in inductive reasoning”, en R. Cattrambone y S. Ohlsson (eds.), Topics in Cognitive Science, 3 (1), págs. 140-153. 
Rogers, T. y McClelland, J. L. (2014): "Parallel Distributed Processing at 25: Further Explorations in the Microstructure of Cognition”, Cognitive Science, 38, págs. 1024-1077.

Rossari, C. (2012): "The evidential meaning of modal parentheticals", Journal of Pragmatics, 44, págs. 2183-2193.

Rouchota, V. (1998): "Procedural Meaning and Parenthetical Discourse Markers", en A. H. Jucker e Y. Ziv (eds.), Discourse Markers. Descriptions and Theory, Ámsterdam, John Benjamins, págs. 97-126.

SCHNEIDER, S. (2007): Reduced parenthetical clauses as mitigators. A corpus study of spoken French, Italian and Spanish, Ámsterdam, John Benjamins.

SLATER et al. (2015): "Spoken Parentheticals in Instructional Discourse in STEM and Non-STEM Disciplines", Talking Matters: Research on talk and communication of international teaching assistants, págs. 3-31.

SLOUTSKY, V. M. (2010): "From perceptual categories to concepts: What develops?", Cognitive Science, 34 (7), págs. 1244-1286.

Traugott, E. y Dasher, R. (2002): Regularity in Semantic Change, Cambridge, Cambridge University Press.

VRIES, M. (DE) (2007): "Invisible constituents? Parentheses as b-merged adverbial phrases”, en N. Dehé e Y. Kavalova (eds.), Parentheticals, Ámsterdam, John Benjamins, págs. 203-234. 